\title{
ACARICIDAS UTILIZADOS NA CITRICULTURA CONVENCIONAL E ORGÂNICA : MANEJO DA LEPROSE E POPULAÇÕES DE ÁCAROS FITOSEÍDEOS ${ }^{1}$
}

\author{
DANIEL JÚNIOR DE ANDRADE², CARLOS AMADEU LEITE DE OLIVEIRA, \\ FERNANDO CÉSAR PATTARO ${ }^{4}$, DIEGO SILVA SIQUEIRA ${ }^{5}$
}

RESUMO-O controle da leprose dos citros no Estado de São Paulo é realizado quase que exclusivamente com aplicações de acaricidas para o controle do ácaro vetor Brevipalpus phoenicis, as quais contribuem para o aumento dos custos de produção e podem afetar negativamente as populações de organismos benéficos. Portanto, o objetivo do trabalho foi avaliar, durante quatro safras, os efeitos de acaricidas indicados para o controle do ácaro $B$. phoenicis em citros convencional e orgânico sobre a evolução da leprose dos citros e sobre ácaros fitoseídeos. O experimento foi instalado em outubro de 2003, em pomar de laranja localizado no município de Reginópolis-SP. $\mathrm{O}$ delineamento experimental foi em blocos casualizados, estabelecendo-se os tratamentos, expressos em $\mathrm{mL}$ de p.c./100 L de água: spirodiclofen a $20 \mathrm{~mL}$ e cyhexatin a $50 \mathrm{~mL}$ (aplicados em rotação), calda sulfocálcica a 4.000 $\mathrm{mL}$ e testemunha sem aplicação de acaricidas. Entretanto, a rotação entre spirodiclofen e cyhexatin iniciou-se em setembro de 2006 e, anteriormente a esse período, utilizou-se somente o spirodiclofen. A cada quinze dias, foram realizados levantamentos populacionais do ácaro B. phoenicis e dos ácaros predadores Iphiseiodes zuluagai e os do gênero Euseius. O nível de controle adotado para o B. phoenicis foi de $8,3 \%$, sendo que as aplicações dos produtos foram realizadas com pulverizador de arrasto tratorizado munido com lanças manuais. Na safra de 2007-2008, coletaram-se 10 frutos caídos devido à leprose por parcela e quantificou-se o número de lesões de leprose presentes em cada fruto. Avaliaram-se, ao término da safra de 2007-2008, a produtividade, as perdas devido à leprose, bem como a incidência e a severidade da leprose. Constatou-se que o local das lesões no fruto é mais importante para determinar sua queda do que o número de lesões presentes. Quanto mais intensa a infestação do ácaro $B$. phoenicis, maior é o número de lesões de leprose, resultando em maior queda prematura de frutos. Os acaricidas spirodiclofen e cyhexatin e spirodiclofen em rotação proporcionaram controle mais eficiente de B. phoenicis, em relação à calda sulfocálcica, resultando em maior produtividade, menores perdas de frutos e nos menores níveis de severidade da leprose. As aplicações de calda sulfocálcica reduziram os níveis populacionais do ácaro $B$. phoenicis abaixo do nível de controle, porém não evitaram o surgimento de lesões de leprose. As aplicações dos acaricidas apresentaram efeito nocivo sobre os ácaros fitoseídeos, pois houve redução da densidade populacional. Termos para indexação: Brevipalpus phoenicis, Vírus da leprose dos citros - CiLV, Citrus sinensis e Seletividade.

\section{ACARICIDES USED IN CONVENTIONALAND ORGANIC CITRUS ORCHARD: LEPROSIS AND PHYTOSEIID MITES POPULATION CONTROL}

\begin{abstract}
The citrus leprosis control in São Paulo state is performed exclusively by acaricides to control the vector mite, Brevipalpus phoenicis, which increases the production costs and may affect the beneficial organism's population. Therefore, the aim of this trial was to evaluate during four seasons, the effects of acaricides recommended to control the mite B. phoenicis in conventional and organic citrus over evolution of citrus leprosis and over phytoseiids' population. The experiment was installed in October of 2003 in a citrus orchard in Reginópolis city, state of São Paulo. The experimental design used randomized blocks, the dosages was expressed as mL c.p./ $100 \mathrm{~L}$ of water and the treatments were the following: spirodiclofen $(20 \mathrm{~mL})$; cyhexatin $(50 \mathrm{~mL})$ (used in rotation), lime sulfur $(4,000 \mathrm{~mL}$ ) and control (without pesticide application). However, the rotation between spirodiclofen and cyhexatin began in September 2006. Prior to that time, only spirodiclofen had been used. Surveys were conducted every 15 days on the B. phoenicis, Iphiseioides zuluagai, and Euseius populations. The control level adopted by the B. phoenicis was $8.3 \%$, and the pesticide applications were conducted using tractor-sprayers. During the 2007-08 seasons, 10 infected fallen fruits per plot were collected and the number of leprosis lesions was quantified by each fruit. By the end of the 2007-08 seasons, the productivity, harvest losses, the disease incidence and severity were evaluated. It was found that the lesions' location over the fruit is more important in determining its drop than the lesions' number. The more intense the mite infestation, the greater is the number of lesions, resulting in increased premature fruit drop. A strategy using acaricides spirodiclofen and cyhexatin in rotation promoted more efficient control of B. phoenicis compared to lime sulfur, resulting in greater productivity, lower fruit losses and severity levels. The lime sulfur applications reduced the mite population incidence below the control level; however it did not prevent the lesions' occurrence. The acaricides applicarevented adverse effects on phytoseiid population because there was a reduction of their density.
\end{abstract}

Index terms: Brevipalpus phoenicis, Citrus Leprosis Virus - CiLV, Citrus sinensis, Selectivity.

\footnotetext{
'(Trabalho 253-09). Recebido em: 30-10-209. Aceito para publicação em: 28-07-2010.

${ }^{2}$ Doutorando em Agronomia/Entomologia Agrícola, FCAV/UNESP. Jaboticabal-SP. Bolsista FAPESP. E-mail: danieldwv@yahoo.com.br ${ }^{3}$ Prof. Dr. Titular, Departamento de Fitossanidade, FCAV/UNESP. Jaboticabal - SP. E-mail: amadeu@fcav.unesp.br

${ }^{4}$ Doutor em Entomologia Agrícola, FCAV/UNESP. Jaboticabal-SP. E-mail: fcpattaro@ctc.com.br

${ }^{5}$ Mestrando em Agronomia/Produção Vegetal, FCAV/UNESP. Jaboticabal - SP. Bolsista FAPESP. E-mail: diego_silvasiqueira@yahoo.com.br
} 


\section{INTRODUÇÃO}

Uma das principais dificuldades enfrentadas pela citricultura refere-se ao aspecto fitossanitário. Entre as doenças, destaca-se a leprose dos citros, considerada como a doença viral de maior importância econômica para a citricultura brasileira, devido aos gastos necessários para o controle do ácaro vetor Brevipalpus phoenicis (LOCALI et al., 2004).

A principal tática de manejo da leprose está pautada na aplicação de acaricidas para o controle do B. phoenicis (BASSANEZI, 2001). Além do elevado custo, o uso constante de agrotóxicos é responsável por grande parte da contaminação do homem e do ambiente, bem como pelo aumento de populações de pragas resistentes (ALVES et al., 2000). Diante disto, mundialmente, ocorreu na última década um elevado interesse pelo consumo de produtos oriundos da agricultura orgânica, cujo sistema de produção se preocupa com a manutenção da qualidade do ambiente e dos alimentos, sendo uma tentativa de reduzir os exageros eventualmente relacionados à agricultura convencional e produzir alimentos mais saudáveis.

Entretanto, Turra e Ghisi (2004) ressaltaram que os produtores de citros orgânicos no Brasil vêm enfrentado dificuldades, principalmente quanto ao tratamento fitossanitário, devido à limitação de uso de agrotóxicos permitidos. Em citros orgânicos, a calda sulfocálcica é um dos poucos produtos químicos aceitos pelo IBD - Instituto Biodinâmico de Desenvolvimento Rural. A calda sulfocálcica é utilizada principalmente para o controle do ácaro-da-leprose B. phoenicis e da-ferrugem-dos-citros Phyllocoptruta oleivora. Porém, devido à não existência de outro produto com mecanismo de ação diferente, aceito na citricultura orgânica, sua recomendação deve ser sempre criteriosa e associada a outras estratégias de manejo com o intuito de dificultar a seleção de populações de ácaros resistentes (PATTARO, 2003).

Dentro desse contexto, a preservação e o aumento na densidade populacional dos inimigos naturais são estratégias que podem auxiliar no manejo de ácaros-praga na cultura dos citros (POLETTI; OMOTO, 2005). A combinação de estratégias de controle químico e biológico constitui uma forma de manejo mais racional, pois o efeito do controle químico não deve ser avaliado somente sobre a interação entre planta hospedeira e praga, mas também sobre o terceiro nível trófico (WRIGHT; VERKERK, 1995). Outra alternativa que tem sido recomendada para um balanço ecológico entre os ácaros-praga e os inimigos naturais refere-se ao uso de produtos seletivos aos ácaros predadores, que são os principais inimigos naturais dos ácaros-praga.
Todavia, estudos que envolvam o impacto provocado por sucessivas aplicações de acaricidas no manejo da leprose e sobre os ácaros predadores durante várias safras ainda são escassos. Em razão disto, objetivou-se avaliar os efeitos da utilização de acaricidas direcionados ao controle do ácaro $B$. phoenicis durante quatro safras, sobre a evolução da leprose e sobre ácaros fitoseídeos, gerando informações que possam ser empregadas nas citriculturas convencional e orgânica.

\section{MATERIAL E MÉTODOS}

Os dados apresentados neste trabalho foram obtidos em um experimento instalado em outubro de 2003, na Fazenda São Pedro, propriedade pertencente ao Grupo Branco Peres, localizada no Município de Reginópolis-SP.

A região onde foi instalado o experimento tem uma altitude de $900 \mathrm{~m}$, sendo o tipo climático da região, segundo a classificação de Köeppen (1970), Cwa, subtropical seco no inverno, e o solo da área experimental classificado como Latossolo VermelhoAmarelo (LVA). As plantas utilizadas foram da variedade 'Pera', enxertadas sobre tangerina 'Cleópatra', com 17 anos de idade, espaçadas 7 × 4 metros e irrigadas por gotejamento.

$\mathrm{O}$ delineamento experimental adotado foi o de blocos casualizados, estabelecendo-se os seguintes tratamentos, expressos em $\mathrm{mL}$ de p.c./100 L de água: spirodiclofen (Envidor $\left.{ }^{\circledR}\right)$ a $20 \mathrm{~mL}$ e cyhexatin (Sipcatin $\left.{ }^{\circledR}\right)$ a $50 \mathrm{~mL}$ (aplicados em rotação); calda sulfocálcica (Fertibom Super $\mathrm{S}{ }^{\circledR}$ ) a $4.000 \mathrm{~mL}$ e testemunha sem aplicação de acaricida, totalizando 3 tratamentos, repetidos 48 vezes, sendo cada repetição composta por 3 plantas dispostas em linha. Porém, a rotação entre os acaricidas spirodiclofen e cyhexatin iniciou-se em setembro de 2006 e, anteriormente a esse período, utilizou-se somente o spirodiclofen.

A cada quinze dias, realizaram-se levantamentos populacionais de B. phoencis. Em cada parcela, amostrou-se a planta central, da qual foram vistoriados, aleatoriamente, três frutos localizados no interior da copa das plantas e de preferência com verrugose, com auxílio de lupa de campo de 10 vezes de aumento (MARTINELLI et al., 1976). $\mathrm{Na}$ ausência de frutos, avaliaram-se três ramos, em início de suberificação, com aproximadamente 25 $\mathrm{cm}$ de comprimento, desprezando-se as brotações (PATTARO, 2003). Durante os levantamentos, também foram quantificados os ácaros predadores da espécie Iphiseiodes zuluagai (Denamark \& Muma) e do gênero Euseius, presentes em cada fruto ou ramo 
amostrado.

Para a determinação do nível de infestação de $B$. phoenicis, considerou-se infestado o fruto que apresentava pelo menos um ácaro em qualquer fase de desenvolvimento. O nível de controle adotado para os tratamentos em que constavam aplicações de acaricidas foi de 8,3\%. As aplicações dos acaricidas foram realizadas com pulverizador de arrasto tratorizado munido com lanças manuais ("tipo pistola"), utilizando volume de calda até além do ponto de escorrimento para proporcionar completa cobertura das plantas.

Os frutos caídos devido à leprose, quinzenalmente, foram coletados e pesados. Antes da realização da colheita, em setembro de 2008 , recolheram-se aleatoriamente 10 frutos do chão, por parcela, caídos devido à leprose e, nestes, quantificou-se o número de lesões de leprose. Nas colheitas, realizaram-se, separadamente, as pesagens dos frutos sadios e dos frutos com lesões de leprose. $\mathrm{O}$ peso dos frutos caídos em cada parcela, coletados quinzenalmente, foi somado ao peso dos frutos lesionados, para cálculo das perdas totais devido à leprose.

Durante os meses de abril a julho de 2008, realizaram-se avaliações da severidade da leprose em todas as plantas do experimento, utilizando-se de uma escala visual de notas (Tabela 1). Nas avaliações, cada planta recebeu duas notas, por avaliadores diferentes, sendo considerado para análise dos dados a média das duas notas.

Os dados obtidos, relativos ao número de lesões, notas de severidade da leprose, produção e perda devido à leprose foram transformados em $\ln (\mathrm{x}+5)$ e submetidos à análise de variância pelo teste $\mathrm{F}$, com auxílio do programa computacional Estat da FCAV/UNESP (ESTAT, 1994), e as médias, comparadas pelo teste de Tukey, a $5 \%$ de probabilidade.

\section{RESULTADOS E DISCUSSÃO}

Efeito dos acaricidas sobre $B$. phoenicis e sobre a evolução da leprose dos citros: Na Figura 1 , podem-se observar as flutuações populacionais do ácaro $B$. phoenicis, nos tratamentos com e sem aplicação de acaricidas, desde a instalação do experimento, bem como as aplicações dos acaricidas realizadas no período de novembro de 2003 a outubro de 2008. Inicialmente, verificou-se que a infestação de $B$. phoenicis foi baixa em toda a área experimental. Atribuiu-se esta baixa infestação inicial ao controle eficiente do ácaro realizado anteriormente à instalação do experimento, motivo pelo qual as aplicações dos acaricidas se iniciaram somente em março de 2005, quando as populações do ácaro atingiram o nível de controle.

A rotação entre o acaricida spirodiclofen e cyhexatin, iniciada a partir da safra de 2006-2007, foi adotada como estratégia de manejo da resistência da população do $B$. phoenicis, haja vista que estes dois produtos atuam por mecanismos distintos de ação. Contudo, no tratamento que implicava o uso da calda sulfocálcica, não foi possível adotar a estratégia de rotacionar produtos, devido à não existência de outro acaricida com mecanismo de ação diferente, registrado para citricultura orgânica (PLANETA ORGÂNICO, 2009).

A eficiência no controle do ácaro B. phoenicis foi maior no tratamento com spirodiclofen e, posteriormente, com spirodiclofen e rotação com cyhexatin, devido ao menor número de aplicações necessárias para manter a população do ácaro abaixo do nível de controle. Desde a instalação do experimento, até outubro de 2008, realizaram-se 7 aplicações de spirodiclofen e 4 de cyhexatin, contra 25 aplicações de calda sulfocálcica.

Pattaro (2003) constatou que a calda sulfocálcica, nas dosagens até $80 \mathrm{~L}$ p.c. $/ 2.000 \mathrm{~L}$ de água, apresenta baixa eficiência residual sobre adultos de B. phoenicis, embora, por ação direta, apresentou-se altamente eficiente, até mesmo em baixa concentração do produto $(20 \mathrm{~L}$ p.c./2.000L de água). O autor ressaltou que, para se obter êxito no controle do ácaro-da-leprose com calda sulfocálcica, é importante que se realize uma excelente cobertura da planta, utilizando-se de dosagem correta, volume e equipamento de aplicação adequados, para aumentar as chances de atingir o ácaro.

Pattaro e Oliveira (2005) não recomendam o controle do ácaro B. phoenicis com calda sulfocálcica em aplicações sucessivas, tendo em vista a possibilidade de selecionar indivíduos resistentes ao ingrediente ativo. Todavia, o produto a ser rotacionado deve ter outro mecanismo de ação, pois Casarin et al. (2004) constataram que linhagens do ácaro-da-leprose resistentes ao acaricida propargite mostraram-se também resistentes à calda sulfocálcica, na razão de 4,6 vezes.

Ressalta-se que a utilização da calda sulfocálcica na citricultura convencional pode ser incluída num programa de rotação de produtos, desde que com mecanismos de ação diferentes. Todavia, na orgânica, dado o uso limitado de produtos, sua recomendação deve estar associada a outras estratégias de manejo (PATTARO; OLIVEIRA, 2005).

Observou-se que as infestações do ácaro $B$. 
phoenicis foram menores em todos os tratamentos logo após as colheitas. Essa redução foi atribuída à alteração no tipo de amostra, uma vez que, logo após as colheitas, os levantamentos populacionais passaram a ser realizados principalmente em frutos novos ou ramos, que sabidamente são menos preferidos pelos ácaros B. phoenicis, quando comparados aos frutos mais desenvolvidos (OLIVEIRA, 1986; CHIAVEGATO, 1991).

Na Tabela 2, são apresentados os resultados da análise de variância para as variáveis: número médio de lesões em frutos caídos, severidade da leprose em plantas, produção e perdas devido à leprose.

Observou-se em relação ao número médio de lesões de leprose, que não houve diferenças entre os tratamentos com acaricidas utilizados para o controle do ácaro B. phoenicis; no entanto, no tratamento sem aplicação de acaricidas, o número de lesões foi significativamente maior que nos demais tratamentos. Observou-se que a chance de as primeiras lesões de leprose nos frutos surgirem próximo ao pedúnculo é maior, pois é por onde os ácaros atingem primeiramente os frutos e, ao se alimentarem, podem infectá-los (Figura 2).

De acordo com Marques et al. (2007), a leprose caracteriza-se por produzir lesões restritas aos locais de alimentação do vetor; assim, a necrose provocada pela doença pode limitar o deslocamento do vírus causador da leprose, o Citrus leprosis virus (CiLV), no tecido da planta. Murphy e Carr (2002) afirmam que o sucesso da infecção localizada de um vírus requer de sua replicação e subsequente movimento de células inicialmente inoculadas para células sadias adjacentes, via plasmodesmos.

Com relação à severidade da leprose nas plantas, avaliada por meio de atribuição de notas, constatou-se que a maior severidade da doença ocorreu no tratamento sem aplicação de acaricidas, diferindo estatisticamente dos demais tratamentos (Tabela 2). As aplicações de calda sulfocálcica não foram capazes de evitar o surgimento de lesões em folhas, ramos e frutos, e os tratamentos em que se empregou a calda, apresentaram uma progressão da severidade da leprose intermediária, no decorrer das quatro safras, quando comparado aos demais tratamentos (Figura 3).

O controle mais eficaz de B. phoencis, proporcionado pela rotação entre spirodiclofen/ cyhexatin, resultou em menor severidade de leprose nas plantas e, por consequência, garantiu maior produção e menores perdas devido à leprose (Figura 4).

Observou-se que o tratamento sem aplicação de acaricida, onde a infestação de $B$. phoenicis foi maior, apresentou a menor produção e intensa queda de frutos lesionados por leprose, indicando que o controle do ácaro vetor é indispensável no manejo da leprose em cultura de citros suscetíveis à doença.

Para o controle da leprose em produção convencional, o uso do spirodiclofen em alternância com o cyhexatin mostrou-se eficiente e viável. A utilização de somente calda sulfocálcica para a produção de citros orgânicos não foi suficiente para controlar a leprose. Uma das alternativas para melhorar o desempenho da calda sulfocálcica seria reduzir o nível de controle; entretanto, isso implicaria o aumento do número de aplicações, que além de onerar os custos de produção, contribuiria para o aumento da contaminação do meio ambiente. Com o aumento do número de aplicações, aumenta-se, também, a chance de selecionar populações resistentes ao ingrediente ativo, e como abaixar o nível de controle não é uma medida recomendada, outras estratégias devem ser pesquisadas no sentido de controlar a leprose em pomares de citros orgânicos.

Efeito dos acaricidas sobre ácaros fitoseídeos: Na primeira avaliação da ocorrência dos ácaros I. zuluagai e Euseius spp., que correspondeu ao período de outubro de 2003 a agosto de 2006, no qual foi utilizado somente o spirodiclofen não rotacionado com cyhexatin e calda sulfocálcica, pôde-se verificar que, do total de ácaros fitoseídeos encontrados nas avaliações, $10,3 \%, 33,8 \%$ e $55,9 \%$ foram encontrados nos tratamentos com calda sulfocálcica, spirodiclofen e testemunha sem aplicação, respectivamente (Figura 5). Desta forma, a calda sulfocálcica mostrou-se menos seletiva aos ácaros fitoseídeos em relação ao spirodiclofen, pois houve menor ocorrência destes ácaros nos tratamentos com calda sulfocálcica.

Casarin et al. (2008) avaliaram a toxicidade da calda sulfocálcica (Fertibom super $\mathrm{S}^{\circledR}$ ) ao ácaro I. zuluagai em laboratório, empregando bioensaios de contato direto e residual, e verificaram que este produto, na concentração de $600 \mathrm{ppm}$, reduziu a taxa de crescimento instantânea do fitoseídeo em aproximadamente $50 \%$. Os autores classificaram a calda sulfocálcica segundo a IOBC (International Organization of Biological Control), como nociva ao ácaro predador, enquadrando-a na classe de toxicidade 4.

Hassan et al. (1994) constataram que a calda sulfocálcica a 7\% foi altamente tóxica aos ácaros fitoseídeos das espécies Phytoseiulus persimilis Athias-Henriot, Amblyseius pontentillae (Garman) e Typhlodromus pyri (Scheuten). Silva et al. (2009) avaliaram em laboratório a seletividade da calda sulfocálcica sobre o ácaro Agistemus brasiliensis 
Matioli, Ueckermann e Oliveira pertencente à família Stigmaeidae que, junto com a família Phytoseiidae, constituem-se nos principais inimigos naturais do ácaro $B$. phoenicis. Estes autores verificam alta toxicidade da calda sulfocálcica ao ácaro estigmeídeo, causando mortalidade de $100 \%$ de fêmeas adultas deste, após 72 horas da aplicação sobre os ácaros.

Como mencionado, o spirodiclofen apresentou maior seletividade sobre os ácaros fitoseídeos avaliados que a calda sulfocálcica. Esses resultados concordaram com Reis et al. (2005), que constataram que o spirodiclofen (Envidor $240 \mathrm{SC}^{\circledR}$ ) apresenta seletividade fisiológica sobre fêmeas adultas dos ácaros fitoseídeos pertencentes às espécies Euseius citrifolius Denmark \& Muma, Amblyseius herbicolus Chant e Euseius alatus DeLeon, sendo classificados como levemente nocivos às duas primeiras espécies e moderadamente nocivo à terceira espécie citada. No entanto, os autores ressaltaram que, apesar da baixa mortalidade de fêmeas adultas ocasionada pelo spirodiclofen, houve redução do número de ovos postos em relação aos padrões hexythiazox e óxido de fenbutatin. Diante disso, embora o spirodiclofen tenha apresentado efeito prejudicial aos ácaros predadores, Wolf e Schnorbach (2002), citados por Reis et al. (2005), consideram que o produto não representa risco para esses predadores a campo, pois os efeitos sobre eles são baixos, e as populações afetadas recuperam-se rapidamente.

Nos levantamentos populacionais realizados no período de setembro de 2006 a outubro de 2008, quando foi utilizado spirodiclofen rotacionado com cyhexatin, observou-se que 33,0\% desses ácaros foram encontrados nas plantas tratadas com calda sulfocálcica, 23,34\% nas tratadas com spirodiclofen e cyhexatin em rotação e $43,66 \%$ nas sem tratamento com acaricidas (Figura 6). Comparativamente ao período anterior, verificou-se que houve menor ocorrência de ácaros fitoseídeos nos tratamentos com spirodiclofen e cyhexatin aplicados em rotação. Um dos fatores para explicar esse resultado pode ser atribuído à menor seletividade do cyhexatin sobre ácaros fitoseídeos com relação ao spirodiclofen.

Diversos trabalhos, realizados principalmente no Brasil, constataram que o cyhexatin apresenta elevada toxicidade sobre adultos de algumas espécies de fitoseídeos, tanto em condições de laboratório quanto em campo (KOMATSU; NAKANO, 1988; YAMAMOTO et al., 1992; SATO et al., 1995; REIS et al., 1999; SILVA; OLIVEIRA, 2007).

Contudo, os dados apresentados na literatura para os acaricidas organoestânicos, quanto ao efeito sobre ácaros fitoseídeos, não são consistentes.
Segundo Jacobson et al. (1999), os organoestânicos não possuem efeito sobre ovos de ácaros, todavia apresentam elevado efeito tóxico sobre larvas eclodidas, fato este comprovado por Reis e Souza (2001), que verificaram que os acaricidas organoestânicos óxido de fenbutatin e chlorfenapyr não apresentam efeito ovicida aos ácaros predadores I. zuluagai e E. alatus, porém causam elevada mortalidade de larvas. Chiaradia e Cruz (1997) verificaram em campo que, inicialmente, o cyhexatin afetou a densidade populacional inicial de I. zuluagai, contudo permitiu um rápido restabelecimento da mesma em campo, sugerindo que o acaricida apresenta baixo efeito residual e/ou ovicida sobre esta espécie de ácaro predador. Diante disso, tornase importante a realização de trabalhos que visem a verificar o efeito dos organoestânicos sobre os ácaros predadores e sobre seus ovos, pois, na literatura, são encontrados resultados discordantes com relação à seletividade deste grupo de acaricidas (POLETTI, 2002; REIS; SOUZA, 2001; AMORIM et al., 2006.).

O maior percentual de ocorrência de ácaros predadores nos tratamentos com calda sulfocálcica, neste período de avaliação, pode ser atribuído ao seu controle menos eficiente do ácaro-da-leprose em relação aos acaricidas spirodiclofen e cyhexatin. Pode-se observar que a calda sulfocálcica, apesar de ter sido capaz de reduzir a população do ácaroda-leprose abaixo do nível de controle após as aplicações, não foi capaz de reduzir a população a zero, como constatado nos tratamentos com spirodiclofen e cyhexatin. Possivelmente, a maior infestação do ácaro-da-leprose e em patamares mais elevados tenha favorecido a população dos predadores devido à maior disponibilidade de alimento. Além disso, a frequente aplicação de calda sulfocálcica pode ter aumentado a frequência de ácaros resistentes, tanto a dos ácaros-praga como a dos predadores, explicando, em parte, a maior ocorrência dos ácaros predadores nestes tratamentos com aplicações sucessivas de calda sulfocálcica. 
TABELA 1 - Escala visual de notas para a avaliação da severidade da leprose em plantas de citros (RODRIGUES, 2000).

\begin{tabular}{cl}
\hline Notas & \multicolumn{1}{c}{ Sintomas de leprose em plantas de citros } \\
\hline 0 & Ausência de lesões \\
1 & Poucas lesões em qualquer órgão, restritas a um setor da planta \\
2 & Lesões em mais de um órgão e/ou distribuídas em mais de um setor \\
3 & Lesões abundantes em todos os órgãos e bem distribuídas pela planta \\
4 & Lesões abundantes (toda planta) e queda de folhas e/ou frutos \\
5 & Anterior (4) + seca e morte de ramos \\
\hline
\end{tabular}

TABELA 2 - Resumo da análise de variância e testes de significância para as variáveis: número médio de lesões por fruto cítrico, severidade da leprose, produção e perdas devido à leprose (safra de 2007-2008). Fazenda São Pedro, Reginópolis-SP

\begin{tabular}{cccccc}
\hline \multicolumn{1}{c}{ Tratamentos } & $\begin{array}{c}\text { Dosagens } \\
\text { mL p.c./100 L }\end{array}$ & $\begin{array}{c}\text { Número de } \\
\text { lesões por fruto }\end{array}$ & $\begin{array}{c}\text { Severidade } \\
\text { da leprose }\end{array}$ & $\begin{array}{c}\text { Produção } \\
\text { (kg/planta) }\end{array}$ & $\begin{array}{c}\text { Perdas devido } \\
\text { à leprose } \\
\text { (kg/planta) }\end{array}$ \\
\hline Spirodiclofen/cyhexatin & $20 / 50$ & $4,68 \mathrm{~b}$ & $1,90 \mathrm{c}$ & $5,20 \mathrm{a}$ & $3,87 \mathrm{c}$ \\
Calda sulfocálcica & 4.000 & $4,88 \mathrm{~b}$ & $2,19 \mathrm{~b}$ & $4,34 \mathrm{~b}$ & $4,42 \mathrm{a}$ \\
Testemunha & - & $5,21 \mathrm{a}$ & $2,26 \mathrm{a}$ & $2,89 \mathrm{c}$ & $4,13 \mathrm{~b}$ \\
\hline TESTE F & & $13,40^{* *}$ & $95,19^{* *}$ & $122,79 * *$ & $10,60^{* *}$ \\
CV(\%) & 10,13 & 6,37 & 17,61 & 10,33 \\
DMS (TUKEY) & 0,24 & 0,06 & 0,36 & 0,21 \\
\hline
\end{tabular}

Dados originais transformados em $\ln (\mathrm{x}+5) ;(* *)$ significativo a $1 \%$ de probabilidade.

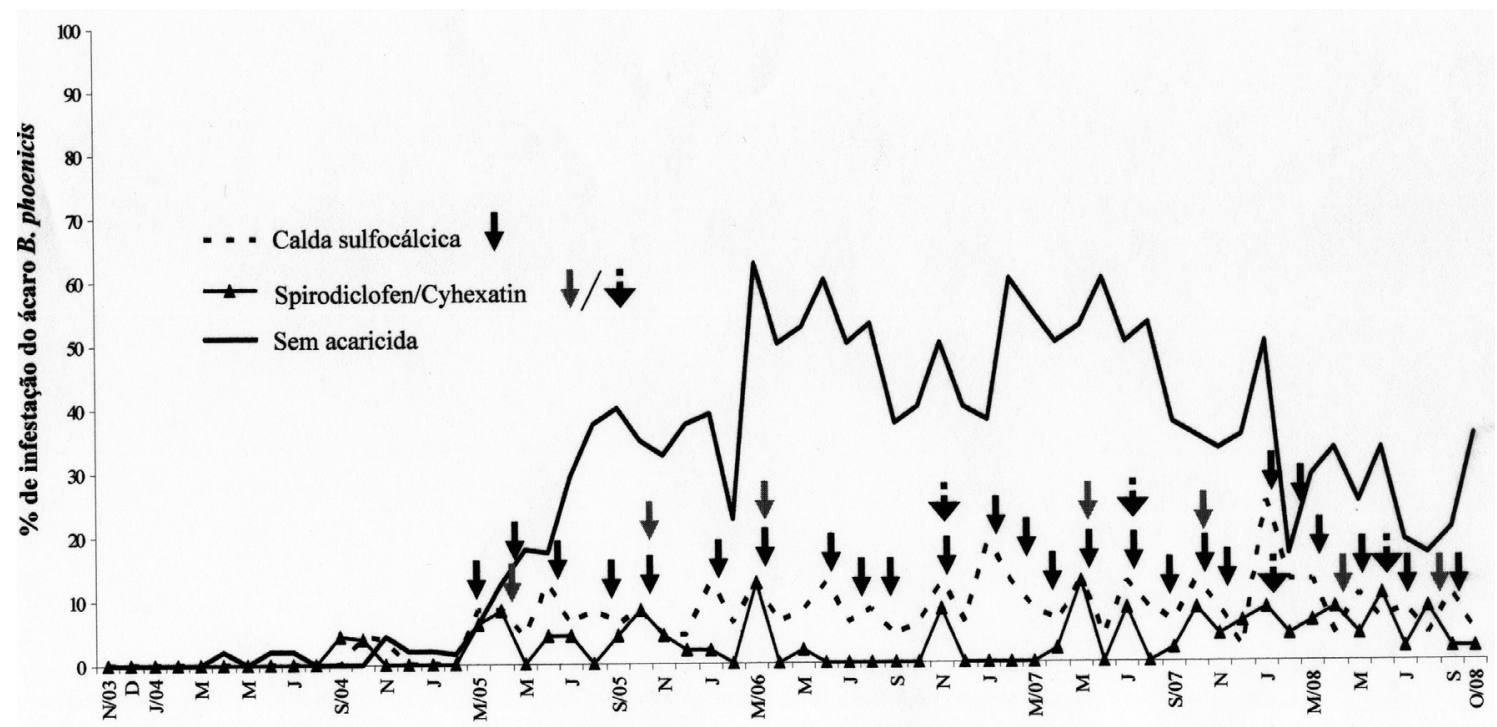

FIGURA 1 - Flutuações populacionais do ácaro Brevipalpus phoenicis, nos tratamentos com e sem acaricidas, e as aplicações dos acaricidas (de novembro de 2003 a outubro de 2008). Fazenda São Pedro, Reginópolis-SP 


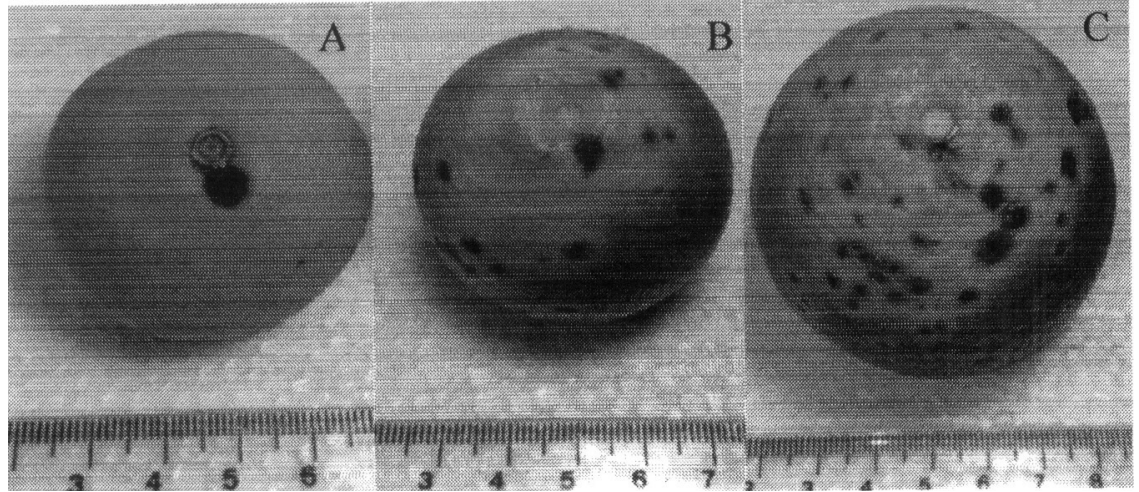

FIGURA 2 - Frutos de laranja 'Pera' coletados no chão, exibindo lesões de leprose. (A) apenas uma lesão no pedúnculo; (B) fruto com número intermediário de lesões; (C) fruto com número elevado de lesões. Fazenda São Pedro, Reginópolis-SP

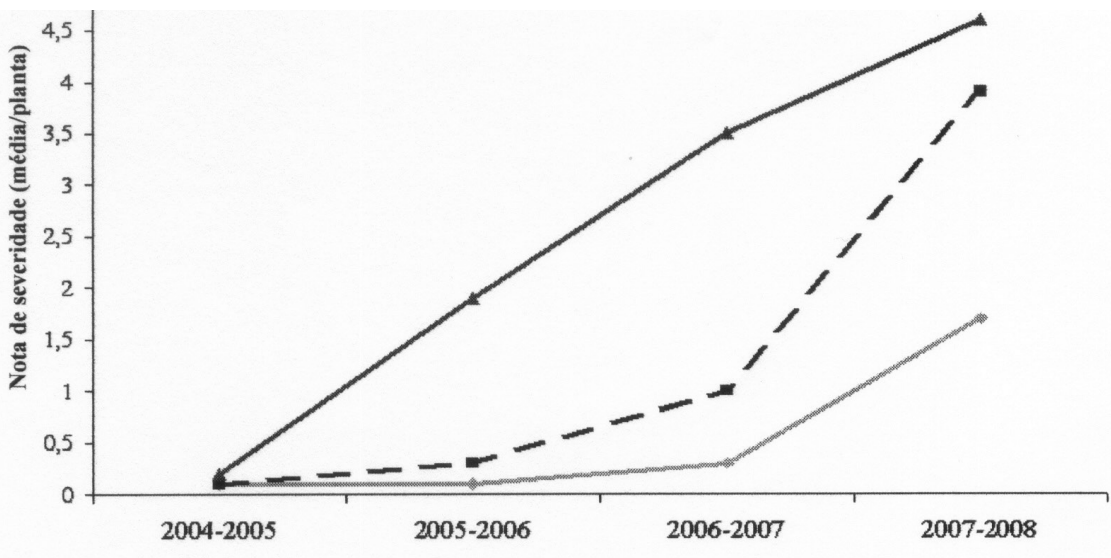

SAFRAS

- spirodiclofen/cyhexatin. $\rightarrow$-calda sulfocálcica $\rightarrow$ sem acaricida

FIGURA 3 - Evolução média da severidade da leprose nas quatro safras, na área experimental, em plantas tratadas ou não com acaricidas. Fazenda São Pedro, Reginópolis-SP

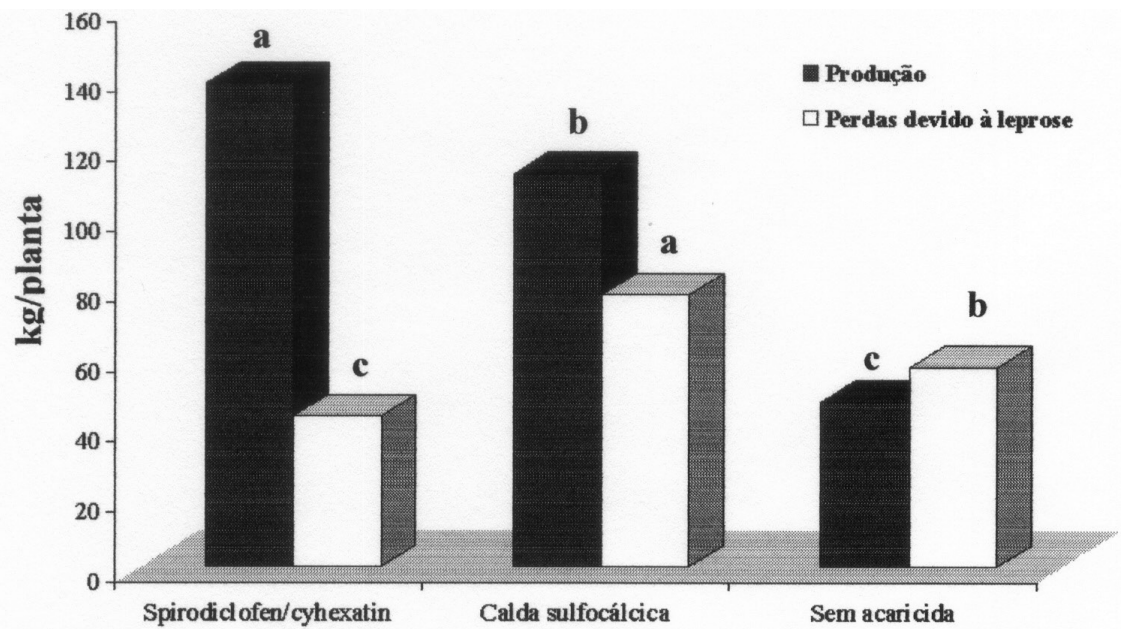

FIGURA 4 - Produção (kg/planta) e perdas devido à leprose ( $\mathrm{kg} /$ planta) obtidas em plantas de citros tratadas com diferentes acaricidas para o controle do ácaro B. phoenicis (safra de 2007-2008). Fazenda São Pedro, Reginópolis-SP 


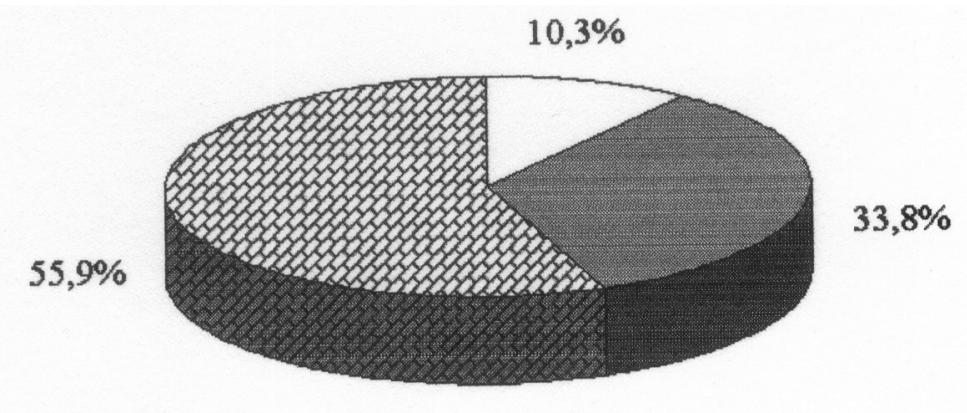

$\square$ calda sulfocálcia

spirodiclofen

国 sem acaricida

FIGURA 5 - Porcentagem de ocorrência de ácaros fitoseídeos (Iphiseiodes zuluagai e Euseius spp.) nos respectivos tratamentos, correspondentes ao período de outubro de 2003 a agosto de 2006. Fazenda São Pedro, Reginópolis-SP

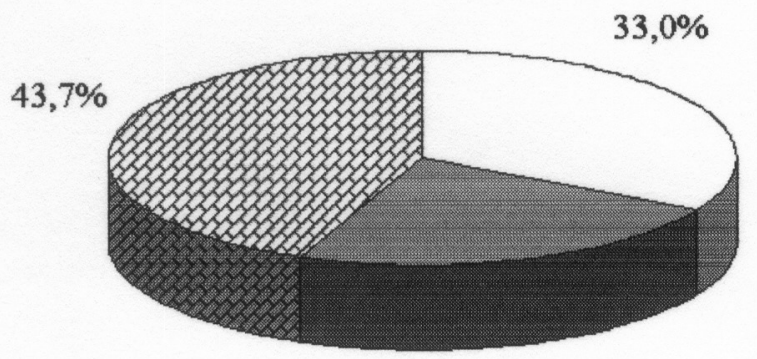

$23,3 \%$

calda sulfocálcia $\quad$ spirodiclofen/cyhexatin sem acaricida

FIGURA 6 - Porcentagem de ocorrência de ácaros fitoseídeos (Iphiseiodes zuluagai e Euseius spp.) nos respectivos tratamentos, correspondente ao período de setembro de 2006 a outubro de 2008. Fazenda São Pedro, Reginópolis-SP

\section{CONCLUSÕES}

1- Quanto maior a infestação do ácaro Brevipalpus phoenicis, maior é o número de lesões de leprose dos citros, intensificando a queda de frutos.

2- A rotação entre os acaricidas spirodiclofen e cyhexatin proporciona um controle mais eficiente de Brevipalpus phoenicis, resultando em maior produtividade e em menores perdas devido à leprose.

3- A calda sulfocálcica mantém a população de Brevipalpus phoenicis abaixo do nível de controle, porém não evita o surgimento de lesões de leprose em ramos, folhas e frutos.
4 - Os acaricidas spirodiclofen, cyhexatin e calda sulfocálcica ocasionam redução das populações dos ácaros predadores Iphiseiodes zuluagai e Euseius spp..

\section{AGRADECIMENTOS}

Os autores agradecem ao Fundo de Defesa da Citricultura-FUNDECITRUS, pelo suporte financeiro à presente pesquisa, e à FAPESP, pela concessão de bolsas de estudos ao primeiro e quarto autores. 


\section{REFERENCIAS}

ALVES, E.B.; OMOTO, C.; FRANCO, C.R. Resistência cruzada entre o dicofol e outros acaricidas em Brevipalpus phoenicis (Geijskes) (Acari: Tenuipalpidae). Anais da Sociedade Entomológica do Brasil, Londrina, v.29, n.4, p.765-771, 2000.

AMORIM, L.C.S.; SILVA, J.L.; GRAVENA, S.; BENVENGA, S.R.; JÚNIOR, N.A. Efeito de acaricidas sobre ovos do ácaro-da-leprose-dos-citros, em diferentes idades. Laranja, Cordeirópolis, v.27, n.2, p.231-242, 2006.

BASSANEZI, R.B. Aspectos da leprose dos citros. Fitopatologia Brasileira, Brasília, v.26, p.246-247, 2001.

CASARIN, N.F.B.; FRANCO, C.R.; ALVES, E.B.; OMOTO, C. Resistência do ácaro-da-leprose Brevipalpus phoenicis (Geijskes, 1939) (Acari: Tenuipalpidae) à calda sulfocálcica. In: CONGRESSO BRASILEIRO DE ENTOMOLOGIA, 20., 2004, Gramado. Resumos... Gramado: SEB, 2004. p.516.

CASARIN, N.F.B.; SILVA, L.O.; ALBUQUERQUE, F.D.F.; OMOTO, C. Toxicidade de calda sulfocálcica ao ácaro predador Iphiseiodes zuluagai Denmark e Muma (Acari: Phytoseiidade) em citros. In: CONGRESSO BRASILEIRO DE ENTOMOLOGIA, 22., 2008, Uberlândia. Anais... Uberlândia: SEB, 2008. CD-ROM

CHIARADIA, L.A.; CRUZ, F.Z. da. Seletividade de acaricidas a artrópodes benéficos em citros. Agropecuária Catarinense, Florianópolis, v.10, n.2, p.62-65, 1997.

CHIAVEGATO, L.G. Ácaros-da-cultura-de-citros. In: RODRÍGUEZ, O.; VIÉGAS, F.; POMPEU JR., J.; AMARO, A.A. Citricultura brasileira. 2.ed. Campinas: Fundação Cargill, 1991. p. 601-641.

ESTAT. Sistema para análises estatísticas (V. 2.0). Jaboticabal: Departamento de Ciências Exatas, Faculdade de Ciências Agrárias e Veterinárias, UNESP, 1994.
HASSAN, S.A.; BIGLER, F.; BOGENSCHÜTZ, H.; BOLLER, E.; BRUN, J.; CALIS, J.N.M.; COREMANS-PELSENEER, J.; DUSO, C.; GROVE, A.; HEIMBACH, U.; HELYER, N.; HOKKANEN, H.; LEWIS, G.B.; MANSOUR, F.; MORETH, L.; POLGAR, L.; SAMSOE-PETERSEN, L.; SAUPHANOR, B.; STÄUBLI, A.; STERK, G.; VAINIO, A.; VEIRE, M. van de; VIGGIANI, G.; VOGT, H. Results of the sixth joint pesticide testing programme of the IOBC/WPRS: workig group "PESTICIDES AND BENEFICIAL ORGANISMS". Entomophaga, Paris, v.39, n.1, p.107-119, 1994.

JACOBSON, R.J.; CROFT, P.; FENLON, J. Response to fenbutatin oxide in populations of Tetranychus urticae Kock (Acari: Tetranychidae) im UK protect crops. Crop Protection, Kellington, v.18, n.1, p.47-52, 1999.

KOMATSU, S.S.; NAKANO, O. Estudos visando ao manejo do ácaro-da-leprose em citros através do ácaro predador Euseius concordis (Acari: Phytoseiidae). Laranja, Cordeirópolis, v.9, n.1, p.125-146, 1988.

LOCALI, E.C.; FREITAS-ASTÚA, J.; MACHADO, M.A. Leprose-dos-citros: biologia e diagnóstico do vírus. Laranja, Cordeirópolis, v.25, n.1, p.53-68, 2004.

MARQUES J.P.R.; FREITAS-ASTÚA, J.; KITAJIMA, E.W.; GLÓRIA B.A. Lesões foliares e de ramos de laranjeira-doce causadas pela leprose-dos-citros. Pesquisa Agropecuária Brasileira, Brasília, v.42, n.11, p.1.531-1.536, 2007.

MARTINELLI, N.M.; OLIVEIRA, C.A.L.de; PERECIN, D. Conhecimentos básicos para estudos que envolvam levantamentos da população do ácaro Brevipalpus phoenicis (Geijskes,1939) na cultura dos citros. Científica, Jaboticabal, v.4, p.242-253, 1976.

MURPHY, A.M.; CARR, J.P. Salicylic acid has cellspecific effects on Tobacco mosaic virus replication and cell-to-cell movement. Plant Physiology, Minneapolis, v.128, p.552-563, 2002.

OLIVEIRA, C.A.L. de. Flutuação populacional e medidas de controle do ácaro-da-leprose Brevipalpus phoenicis (Geijskes, 1939) em citros. Laranja, Cordeirópolis, v.7, p.1-31, 1986. 
PATTARO, F.C. Calda Sulfocálcica no Agrossistema Citrícola. 2003. 73 f. Dissertação (Mestrado em Agronomia - Entomologia Agrícola) - Faculdade de Ciências Agrárias e Veterinárias, Universidade Estadual Paulista, Jaboticabal, 2003.

PATTARO, F.C.; OLIVEIRA, C.A.L.de. Calda sulfocálcica: aplicações e implicações. Campo e Negócios, Uberlândia, v.3, n.28, p.58-61, 2005.

PLANETA ORGÂNICO. Citricultura orgânica. Disponível em: <http://www.planetaorganico.com. br >. Acesso em: 20 fev. 2009.

POLETTI, M. Variabilidades inter e intraespecífica na suscetibilidade de ácaros fitoseídeos (Acari: Phytoseiidae) a dicofol e deltametrina em citros. 2002. 78 f. Dissertação (Mestrado em Ciências Entomologia) - Escola Superior de Agricultura Luiz de Queiroz, 2002.

POLETTI, M.; OMOTO, C. Variabilidades inter e intraespecífica na suscetibilidade de ácaros fitoseídeos à deltametrina em citros no Brasil. Manejo Integrado de Plagas y Agroecología, Turrialba, v.75, p. 32-37, 2005.

REIS, P.R.; PEDRO NETO, M.; FRANCO, R.A. Controle de Brevipalpus phoenicis (Geijskes, 1939) e Oligonychus ilicis (McGregor, 1917) (Acari: Tenuipalpidae, Tetranychidae) em cafeeiro e o impacto sobre ácaros benéficos. II - Spirodiclofen e Azocyclotin. Ciência e Agrotecnologia, Lavras, v.29, n.3, p.528-537, 2005.

REIS, P.R.; SOUZA, E.O. Seletividade de chlorfenapyr e fenbutatin-oxide sobre duas espécies de ácaros predadores (Acari: Phytoseiidae) em citros. Revista Brasileira de Fruticultura, Jaboticabal, v.23, n.3, p.584-588, 2001.

REIS, P.R.; SOUSA, E.O.; ALVES, E.B. Seletividade de produtos fitossanitários ao ácaro predador Euseius alatus De Leon (Acari: Phytoseiidae). Revista Brasileira de Fruticultura, Jaboticabal, v.21, n.3, p.350-355, 1999.
RODRIGUES, J.C.V. Relações patógeno-vetorplanta no sistema leprose dos citros. 2000. $168 \mathrm{f}$. Tese. (Doutorado em Ciências) - Centro de Energia Nuclear na Agricultura, Universidade de São Paulo, Piracicaba, 2000.

SATO, M.E.; RAGA, A.; CERÁVOLO, L.C.; CEZÁRIO, A.C.; ROSSI, A. Efeito da utilização de acaricidas em citros, sobre a população de Brevipalpus phoenicis (Geijskes, 1939) (Acari: Tenuipalpidae) e ácaros predadores (família Phytoseiidae). Scientia Agricola, Piracicaba, v.52, n.2, p.282-286, 1995.

SILVA, M.Z. da; OLIVEIRA, C.A.L. de. Toxicidade de alguns agrotóxicos recomendados na citricultura sobre Neoseiulus californicus (McGregor) (Acari: Phytoseiidae). Revista Brasileira de Fruticultura, Jaboticabal, v.29, n.1, p.085-090, 2007.

SILVA, M.Z.; OLIVEIRA, C.A.L. de; SATO, M.E. Seletividade de produtos fitossanitários sobre o ácaro predador Agistemus brasiliensis Matioli, Ueckermann \& Oliveira (Acari: Stigmaeidae). Revista Brasileira de Fruticultura, Jaboticabal, v.31, n.2, p.388-396, 2009.

TURRA, C.; GHISI, F.A. Produção de laranja orgânica no Brasil: produção, mercado e tendências. In: CONGRESSO DA SOCIEDADE BRASILEIRA DE ECONOMIA E SOCIOLOGIA RURAL, 2004. Cuiabá. Resumos... Cuiabá: SOBER, 2004.

WRIGHT, D.J.; VERKERK, R.H.J. Integration of chemical and biological control systems for arthropods: evaluation in a multitrophic context. Pesticide Science, Londres, v.44, p.207-218, 1995.

YAMAMOTO, P.T.; PINTO, A.S.; PAIVA, P.E.B.; GRAVENA, S. Seletividade de agrotóxicos aos inimigos naturais de pragas dos citros. Laranja, Cordeirópolis, v.13, p.709-755, 1992. 